\title{
Removal of Cr (VI) by Biochar Derived from Six Kinds of Garden Wastes: Isotherms and Kinetics
}

\author{
Qiao-Chu Zhang ${ }^{1}{ }^{\mathbb{D}}$, Cheng-Chen Wang ${ }^{2}$, Jin-Hua Cheng ${ }^{1}$, Cheng-Liang Zhang ${ }^{3}$ and Jing-Jing Yao ${ }^{3, *}$ \\ 1 School of Soil and Water Conservation, Beijing Forestry University, Beijing 100083, China; \\ zhang_qiaochu01@126.com (Q.-C.Z.); Jinhua_cheng@126.com (J.-H.C.) \\ 2 Institute of Environmental Remediation and Human Health, Southwest Forestry University, \\ Kunming 650225, China; wangchengchen88@126.com \\ 3 Environmental Protection Research Institute of Light Industry, Beijing 100089, China; zhang64@126.com \\ * Correspondence: yaojing1989_lucky@163.com
}

check for updates

Citation: Zhang, Q.-C.; Wang, C.-C.; Cheng, J.-H.; Zhang, C.-L.; Yao, J.-J. Removal of Cr (VI) by Biochar Derived from Six Kinds of Garden Wastes: Isotherms and Kinetics. Materials 2021, 14, 3243. https:// doi.org/10.3390/ma14123243

Academic Editor: Benjamín Solsona

Received: 16 May 2021

Accepted: 10 June 2021

Published: 11 June 2021

Publisher's Note: MDPI stays neutral with regard to jurisdictional claims in published maps and institutional affiliations.

Copyright: (C) 2021 by the authors. Licensee MDPI, Basel, Switzerland. This article is an open access article distributed under the terms and conditions of the Creative Commons Attribution (CC BY) license (https:// creativecommons.org/licenses/by/ $4.0 /)$.

\begin{abstract}
Garden waste is one of the main components of urban solid waste which affects the urban environment. In this study, garden waste of Morus alba L. (SS), Ulmus pumila L. (BY), Salix matsudana Koidz (LS), Populus tomentosa (YS), Sophora japonica Linn (GH) and Platycladus orientalis (L.) Franco (CB) was pyrolyzed at $300{ }^{\circ} \mathrm{C}, 500{ }^{\circ} \mathrm{C}, 700{ }^{\circ} \mathrm{C}$ to obtain different types of biochar, coded as SSB300, SSB500, SSB700, BYB300, etc., which were tested for their Cr (VI) adsorption capacity. The results demonstrated that the removal efficiency of $\mathrm{Cr}$ by biochar pyrolyzed from multiple raw materials at different temperatures was variable, and the $\mathrm{pH}$ had a great influence on the adsorption capacity and removal efficiency. GHB700 had the best removal efficiency (89.44\%) at a pH of 2 of the solution containing $\mathrm{Cr}(\mathrm{VI})$. The pseudo second-order kinetics model showed that $\mathrm{Cr}$ (VI) adsorption by biochar was chemisorption. The Langmuir model showed that the adsorption capacity of SSB300 was the largest $\left(51.39 \mathrm{mg} \cdot \mathrm{g}^{-1}\right)$, BYB500 was $40.91 \mathrm{mg} \cdot \mathrm{g}^{-1}$, GHB700, CBB700, LSB700, YSB700 were $36.85 \mathrm{mg} \cdot \mathrm{g}^{-1}, 36.54 \mathrm{mg} \cdot \mathrm{g}^{-1}, 34.53 \mathrm{mg} \cdot \mathrm{g}^{-1}$ and $32.66 \mathrm{mg} \cdot \mathrm{g}^{-1}$, respectively. This research, for the first time, used a variety of garden wastes to prepare biochar, and explored the corresponding raw material and pyrolysis temperature for the treatment of $\mathrm{Cr}$ (VI). It is hoped to provide a theoretical basis for the research and utilization of garden wastes and the production and application of biochar.
\end{abstract}

Keywords: garden waste; biochar; Cr (VI), adsorption; pyrolysis temperature

\section{Introduction}

Urban gardens play an important role in purifying the atmosphere, reducing noise and dust, and reducing the heat island effect $[1,2]$. However, garden waste has become one of the important components of solid waste in cities. According to the report, 10,000 street trees could produce 600 tons of garden waste every year. Taking Beijing as an example, the green area of Beijing reached 900 million square meters, and the dry weight of garden waste exceeded 3 million tons per year [3]. Garden waste refers to the leaves, branches, residual flowers, and fruits produced by natural withering or artificial pruning of garden plants. Garden waste contains $\mathrm{C}, \mathrm{O}, \mathrm{P}, \mathrm{N}, \mathrm{K}, \mathrm{H}, \mathrm{Na}, \mathrm{Mg}, \mathrm{Ca}$, and other elements. It is a kind of organic matter with high nutrient content, low harmful components, and strong availability $[4,5]$. The common disposal methods of garden waste include incineration, landfill and biodegradation. However, incineration will produce a large amount of smoke and toxic substances, which will do great harm to the environment; landfill requires a lot of space, and the cost is high; biological decomposition cannot meet the needs of the sludge, due to its slow efficiency. Therefore, it is urgent to find a suitable way to deal with the quality of landscape architecture. A large number of studies indicate that biochar can be made from organic matter by anaerobic pyrolysis [5,6]. Because of its wide range of raw materials, low cost and good physicochemical properties, it can be used in pollutant treatment and soil improvement $[7,8]$. Chromium was a common pollutant, 
which exists naturally in rocks. It is leached from the surface soil of landfills and coal gangue, and discharged by tanneries, causing pollution to water and terrestrial ecosystems. Plants growing in chromium-affected areas lead to the accumulation of chromium in edible parts. The continuous accumulation of chromium in these plants will cause serious health problems to the human body $[9,10]$. In addition, it will take a long time for these contaminated soils and water sources to be restored to agricultural production using economically applicable and feasible technologies. Therefore, biochar is produced to adsorb and thus immobilize pollutants. There has been a lot of research on agricultural waste, urban sludge, and fruit shell and other raw materials, but less on garden waste. The main purpose of this study was to explore the adsorption capacity and removal efficiency of $\mathrm{Cr}(\mathrm{VI})$ in water by biochar prepared from six kinds of garden waste at different temperatures. In addition, the effects of initial $\mathrm{pH}$ value, reaction time and initial concentration on adsorption and removal of $\mathrm{Cr}(\mathrm{VI})$ by biochar were investigated. Then, the optimal kinetic model and isotherm model of $\mathrm{Cr}$ (VI) on biochar prepared from six kinds of garden waste at different temperatures were elucidated.

\section{Materials and Methods}

\subsection{Raw Materials and Preparation Methods}

The branches of Morus alba L (SS), Ulmus pumila L. (BY), Salix matsudana Koidz (LS), Populus tomentosa (YS), Sophora japonica Linn (GH) and Platycladus orientalis (L.) Franco (CB) were collected at the ecological restoration experimental base (E, $\left.40^{\circ} 9^{\prime} 56.73^{\prime \prime} \mathrm{N}, 116^{\circ} 9^{\prime} 1.04^{\prime \prime}\right)$ of the Environmental Protection Institute of Light Industry, Beijing Academy of Science and Technology. The branches were cleaned from dust and dried at $65^{\circ} \mathrm{C}$ until constant weight. Then, the branches were cut into small sections and placed in a crucible, wrapped with tin foil to reduce air entry. The crucible was placed in a muffle furnace for the pyrolysis. The heating rate was $10^{\circ} \mathrm{C} \cdot \mathrm{min}^{-1}$, the holding time was $60 \mathrm{~min}$, and the reaction temperature of slow pyrolysis is generally within $1000^{\circ} \mathrm{C}[6,11]$. So, in this experiment, the chosen preparation temperatures were $300{ }^{\circ} \mathrm{C}, 500{ }^{\circ} \mathrm{C}$ and $700{ }^{\circ} \mathrm{C}$. The pyrolyzed biochar was cooled to room temperature and taken out, washed with ultrapure water to neutrality, dried, and finally crushed and passed through a 100-mesh sieve. A total of 18 different types of biochar including Morus alba L. biochar (SSB300, SSB500, SSB700), Ulmus pumila L. biochar (BYB300, BYB500, BYB700), Populus tomentosa biochar (YSB300, YSB500, YSB700), Sophora japonica Linn biochar (GHB300, GHB500, GHB700), Platycladus orientalis (L.) Franco biochar (CBB300, CBB500, CBB700), Salix matsudana Koidz biochar (LSB300, LSB500, LSB700) were obtained at three temperatures, and stored in the dryer for use.

\subsection{Adsorption Experiment}

All the experiments were carried out in a $50 \mathrm{~mL}$ polypropylene centrifuge tube, the addition of biochar was $1.2 \mathrm{~g} \cdot \mathrm{L}^{-1}$, the addition of $\mathrm{Cr}$ (VI) solution was $25 \mathrm{~mL}$, the speed of the shaking table was $250 \mathrm{r} \cdot \mathrm{min}^{-1}$ and the temperature $25 \pm 2{ }^{\circ} \mathrm{C}$. In the adsorption experiments with different initial $\mathrm{pH}$ values, the initial $\mathrm{pH}$ value was blended by $0.2 \mathrm{M}$ $\mathrm{NaOH}$ and HCL solution, the biochar was weighed in a centrifuge tube, and $50 \mathrm{mg} \cdot \mathrm{L}^{-1}$ $\mathrm{Cr}$ (VI) solution with $\mathrm{pH}$ values of 2.0, 4.0, 6.0, 8.0 and 10.0 was added. The reaction was carried out in a shaking table for $1440 \mathrm{~min}$. In the adsorption experiment of different reaction time, biochar was weighed in the centrifuge tube, $50 \mathrm{mg} \cdot \mathrm{L}^{-1} \mathrm{Cr}(\mathrm{VI})$ solution with initial $\mathrm{pH}$ value of 2.0 was added, and the reaction time was set as $0,5,10,30,60$, $120,360,720,1440 \mathrm{~min}$. In other adsorption studies, the initial $\mathrm{Cr}$ (VI) concentration was generally set at $5-800 \mathrm{mg} \cdot \mathrm{L}^{-1}$ [12]. Therefore, the initial Cr (VI) concentration was set at $5-400 \mathrm{mg} \cdot \mathrm{L}^{-1}$ in the adsorption experiment of different initial $\mathrm{Cr}(\mathrm{VI})$ concentrations. Biochar was weighed in a centrifuge tube, $\mathrm{Cr}(\mathrm{VI})$ solutions with $\mathrm{pH}$ value of 2.0 and concentrations of $5,10,25,50,100,200$ and $400 \mathrm{mg} \cdot \mathrm{L}^{-1}$ were added, and the reaction time was $1440 \mathrm{~min}$. After the reaction, $0.45 \mu \mathrm{m}$ nylon membrane was used for filtration. The concentration of $\mathrm{Cr}(\mathrm{VI})$ and total $\mathrm{Cr}$ were detected by a UV spectrophotometer and ICP-OES. Three replicates were made for each treatment [13]. 


\subsection{Calculation and Statistical Methods}

The removal efficiency $(\mathrm{R}, \%)$ and adsorption capacity $\left(\mathrm{q}, \mathrm{mg} \cdot \mathrm{g}^{-1}\right)$ of biochar on $\mathrm{Cr}$ (VI) are calculated as follows:

$$
\begin{gathered}
R=\frac{C_{0}-C_{e}}{C_{e}} \times 100 \% \\
q=\frac{C_{o}-C_{e}}{m} V
\end{gathered}
$$

where $C_{0}$ and $C_{\mathrm{e}}$ are the initial and equilibrium concentrations of $\mathrm{Cr}(\mathrm{VI})\left(\mathrm{mg} \cdot \mathrm{L}^{-1}\right), V$ is the volume of solution (L), and $\mathrm{m}$ is the amount of biochar added (g).

The Langmuir and Freundlich models were used for the isotherm:

Langmuir model:

$$
\frac{C_{e}}{q_{e}}=\frac{1}{q_{m} k}+\frac{C_{e}}{q_{m}}
$$

Freundlich model:

$$
\lg q_{e}=\lg K_{F}+\frac{1}{n} \lg C_{e}
$$

where $q_{e}$ is the adsorption capacity at equilibrium $\left(\mathrm{mg} \cdot \mathrm{g}^{-1}\right), q_{m}$ is the maximum adsorption capacity $\left(\mathrm{mg} \cdot \mathrm{g}^{-1}\right), C_{e}$ is the solution concentration at equilibrium $\left(\mathrm{mg} \cdot \mathrm{L}^{-1}\right), n$ is the Freundlich equilibrium parameter, and $k$ is the Langmuir equilibrium parameter $\left(\mathrm{L} \cdot \mathrm{mg}^{-1}\right)$, indicating the adsorption strength, which is related to the properties of the adsorption system and usually greater than $1, \mathrm{n}$ determines the shape of the isotherm. It is generally believed that $0.1<1 / n<0.5$ is easy to adsorb, and $1 / n>2$ is difficult to adsorb. $K_{F}$ is the adsorption capacity $\left(\mathrm{mg} \cdot \mathrm{g}^{-1}\right)$. Using $K_{F}$ and $n$, the characteristics of different adsorbents can be compared.

The kinetic model uses pseudo first-order and pseudo second-order kinetic models:

Pseudo first-order kinetic model:

$$
\ln \left(q_{e}-q_{t}\right)=\ln q_{e}-k_{1} t
$$

Pseudo second-order kinetic model:

$$
\frac{t}{q_{t}}=\frac{1}{k_{2} q_{e}^{2}}+\frac{t}{q_{e}}
$$

where $t(\mathrm{~min})$ is the adsorption time, $q_{t}$ is the adsorption capacity at time $t\left(\mathrm{mg} \cdot \mathrm{g}^{-1}\right), q_{e}$ is the adsorption capacity at equilibrium $\left(\mathrm{mg} \cdot \mathrm{g}^{-1}\right), K_{1}\left(\mathrm{~min}^{-1}\right)$ and $K_{2}\left(\mathrm{~g} \cdot \mathrm{mg}^{-1} \cdot \mathrm{h}^{-1}\right)$ are the rate constants for the pseudo first-order and pseudo second-order kinetics, respectively.

\section{Results and Discussion}

\subsection{Effect of Initial $\mathrm{pH}$ on $\mathrm{Cr}(\mathrm{VI})$ Removal}

As we all know, the $\mathrm{pH}$ value is one of the important factors that affects the adsorption process. Actually, it is a key factor to determine the adsorption capacity of biochar for metal ions, especially for biochar containing amino functional groups, which are easily protonated or deprotonated, thus forming different surface charges in solutions with different $\mathrm{pH}$ values $[14,15]$. The influence of biochar on the removal efficiency of $\mathrm{Cr}(\mathrm{VI})$ in the $\mathrm{pH}$ range of 2-10 was studied. The removal efficiency of $\mathrm{Cr}(\mathrm{VI})$ depends largely on the $\mathrm{pH}$ value of the solution (Figure 1). When the $\mathrm{pH}$ value grew from 2.0 to 10.0, the removal efficiency decreased from $89.44 \%$ to $1.56 \%$. The highest removal efficiency was observed at $\mathrm{pH} 2.0$, demonstrating the effect of solution $\mathrm{pH}$ on the $\mathrm{Cr}(\mathrm{VI})$ removal. Other studies have also reported a similar decrease in $\mathrm{Cr}(\mathrm{VI})$ removal efficiency with the increase of $\mathrm{pH}$ [16]. The reason why the $\mathrm{Cr}(\mathrm{VI})$ removal efficiency is higher in acidic solution is that $\mathrm{Cr}$ (VI) mainly exists in $\mathrm{HCrO}_{4}{ }^{-}$form in acidic solution, but it is $\mathrm{CrO}_{4}{ }^{2-}$ in alkaline solution $[12,17]$. The adsorption free energy of $\mathrm{CrO}_{4}{ }^{2-}$ was higher than that of $\mathrm{HCrO}_{4}{ }^{-}$[18]. Therefore, $\mathrm{HCrO}_{4}{ }^{-}$ was more likely to generate electrostatic attraction between the protonated biochar surface 
and the positively charged biochar surface [19]. The $\mathrm{pH}$ of the solution increased, the $\mathrm{OH}^{-}$ions gradually increased, and the $\mathrm{Cr}$ (VI) morphology changed from $\mathrm{HCrO}_{4}{ }^{-}$to $\mathrm{CrO}_{4}{ }^{2-}$ [12]. This leads to the competition between $\mathrm{CrO}_{4}{ }^{2-}$ and more $\mathrm{OH}^{-}$ions, because deprotonation makes the surface of biochar negatively charged [17], the attraction between $\mathrm{Cr}$ (VI) and biochar was critically inhibited [20]; in the meantime, the reduction of $\mathrm{Cr}$ (VI) was another removal mechanism under acidic conditions [21,22], $\mathrm{HCrO}_{4}{ }^{-}$has higher redox potential than $\mathrm{CrO}_{4}{ }^{2-}$ [23]. The results showed that the oxidation ability of $\mathrm{HCrO}_{4}{ }^{-}$ was higher than that of $\mathrm{CrO}_{4}{ }^{2-}$, so the reduction removal ability of biochar for $\mathrm{CrO}_{4}{ }^{2-}$ was lower than that of $\mathrm{HCrO}_{4}{ }^{-}$, so the removal efficiency of $\mathrm{Cr}$ (VI) was higher under acidic conditions.
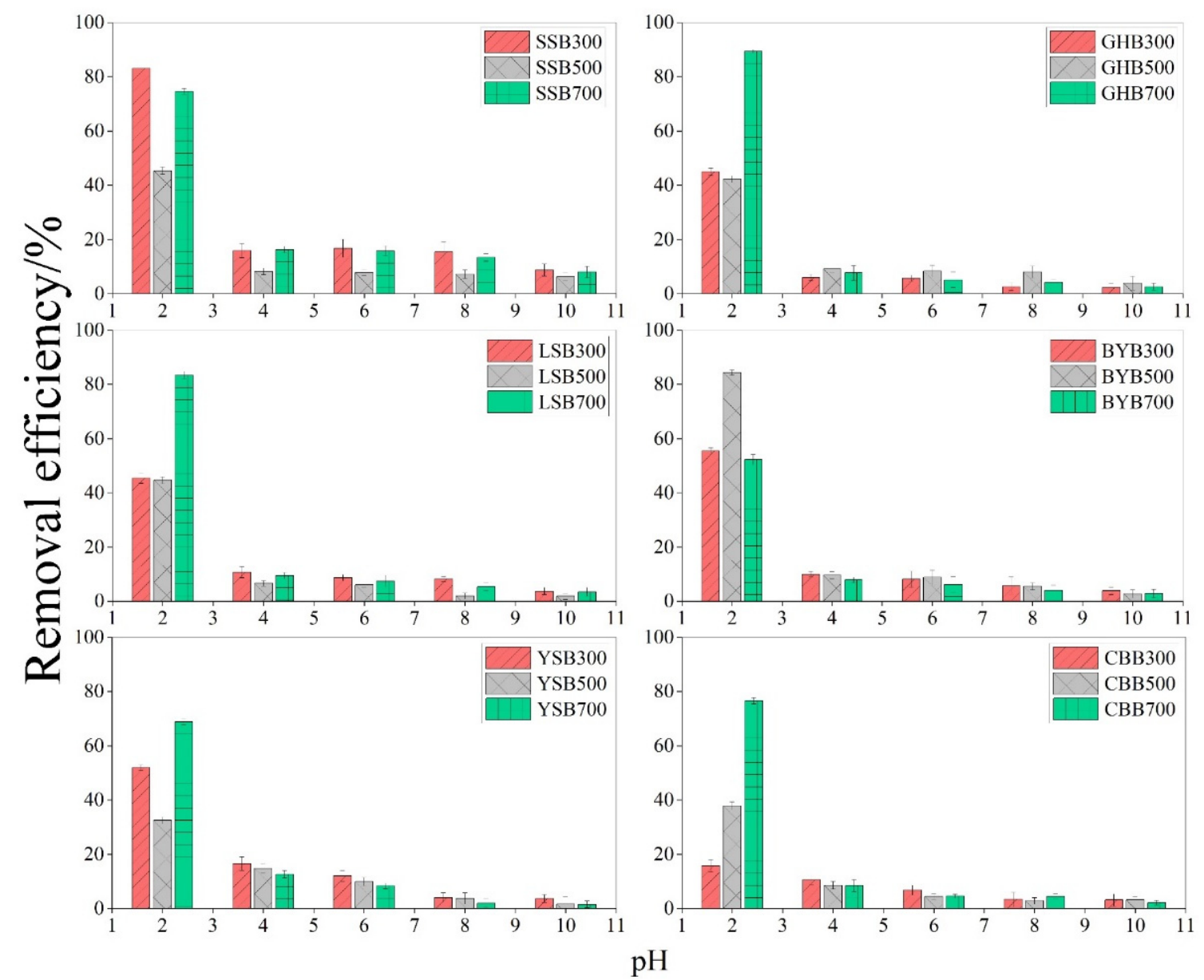

Figure 1. Relationship between $\mathrm{pH}$ value and $\mathrm{Cr}(\mathrm{VI})$ removal efficiency (initial $\mathrm{Cr}(\mathrm{VI})$ concentration: $50 \mathrm{mg} \cdot \mathrm{L}^{-1}$; dosage of biochar: $\left.1.2 \mathrm{~g} \cdot \mathrm{L}^{-1}\right)$, different letters show significant differences at $\alpha=0.05$.

\subsection{Effect the Different Biochars on Cr(VI) Removal}

The removal efficiency results of different types of biochar can be seen from Figure 2. When the initial $\mathrm{pH}$ value of the solution was 2.0, the biochar with different raw materials and temperatures had a strong removal efficiency of $\mathrm{Cr}(\mathrm{VI})$, and the difference was significant. The removal efficiency from high to low were as follows: GHB700, BYB500, LSB700, SSB300, CBB700, SSB700, YSB700, BYB300, BYB700, YSB300, LSB300, SSB500, GHB300, LSB500, GHB500, CBB500, YSB500, CBB300 (89.44\%, 84.34\%, 83.43\%, 83.06\%, $76.57 \%, 74.55 \%, 68.86 \%, 55.42 \%, 52.28 \%, 51.93 \%, 45.40 \%, 45.36 \%, 44.98 \%, 44.71 \%, 42.25 \%$, $37.89 \%, 32.51 \%, 15.77 \%)$. The highest removal efficiency was GHB700 (89.44\%), the lowest was CBB300. The removal efficiency was only $15.77 \%$, the difference was about 6 times. When the $\mathrm{pH}$ value was 2.0 and the pyrolysis temperature is the same, the removal of $\mathrm{Cr}$ (VI) by biochar was obviously different (Figure 3). For example, when the pyrolysis 
temperature was $300{ }^{\circ} \mathrm{C}$, the highest removal efficiency of GHB $(89.44 \%)$ was 5.7 times that of CCB $(15.77 \%)$; when the pyrolysis temperature was $500{ }^{\circ} \mathrm{C}$, the highest removal efficiency was BYB $(84.34 \%)$, the lowest removal efficiency was YSB $(32.51 \%)$, with a difference of a factor of 2.6; when the pyrolysis temperature was $700{ }^{\circ} \mathrm{C}$, the highest removal efficiency was GHB (89.43\%), the lowest was YSB (52.28\%), and the difference between the highest and the lowest was a factor of 1.7. This showed that raw materials had great influence on the removal of $\mathrm{Cr}$ (VI) [24]. Moreover, with the increase of the pyrolysis temperature of raw materials, the difference of $\mathrm{Cr}$ (VI) removal efficiency gradually decreased, which indicated that the chemical and physical properties of some biochar types were improved with the rise of pyrolysis temperature, for example, the removal efficiency of $\mathrm{CBB}, \mathrm{GHB}$ and LSB increased from $15.77 \%, 44.98 \%$ and $45.40 \%$ to $76.57 \%, 89.44 \%$ and $83.43 \%$ respectively with the rise of temperature. When the $\mathrm{pH}$ value was 2.0 and the raw materials were the same, the removal of Cr (VI) was also different, such as, the removal efficiency of GHB300, GHB500 and GHB700 was $44.98 \%, 42.25 \%$ and $89.44 \%$ respectively; the removal efficiency of CCB300, CCB500 and CBB700 was $15.77 \%, 37.89 \%$ and $76.57 \%$, respectively. When the reaction conditions were fixed, the removal efficiencies of different types of biochar were different, because different raw materials will form different kinds and quantities of functional groups and pores with different numbers, sizes and distributions at different pyrolysis temperatures, due to different element compositions, resulting in great differences in the composition and properties of biochar, thus affecting the removal capacity of biochar [5,6].

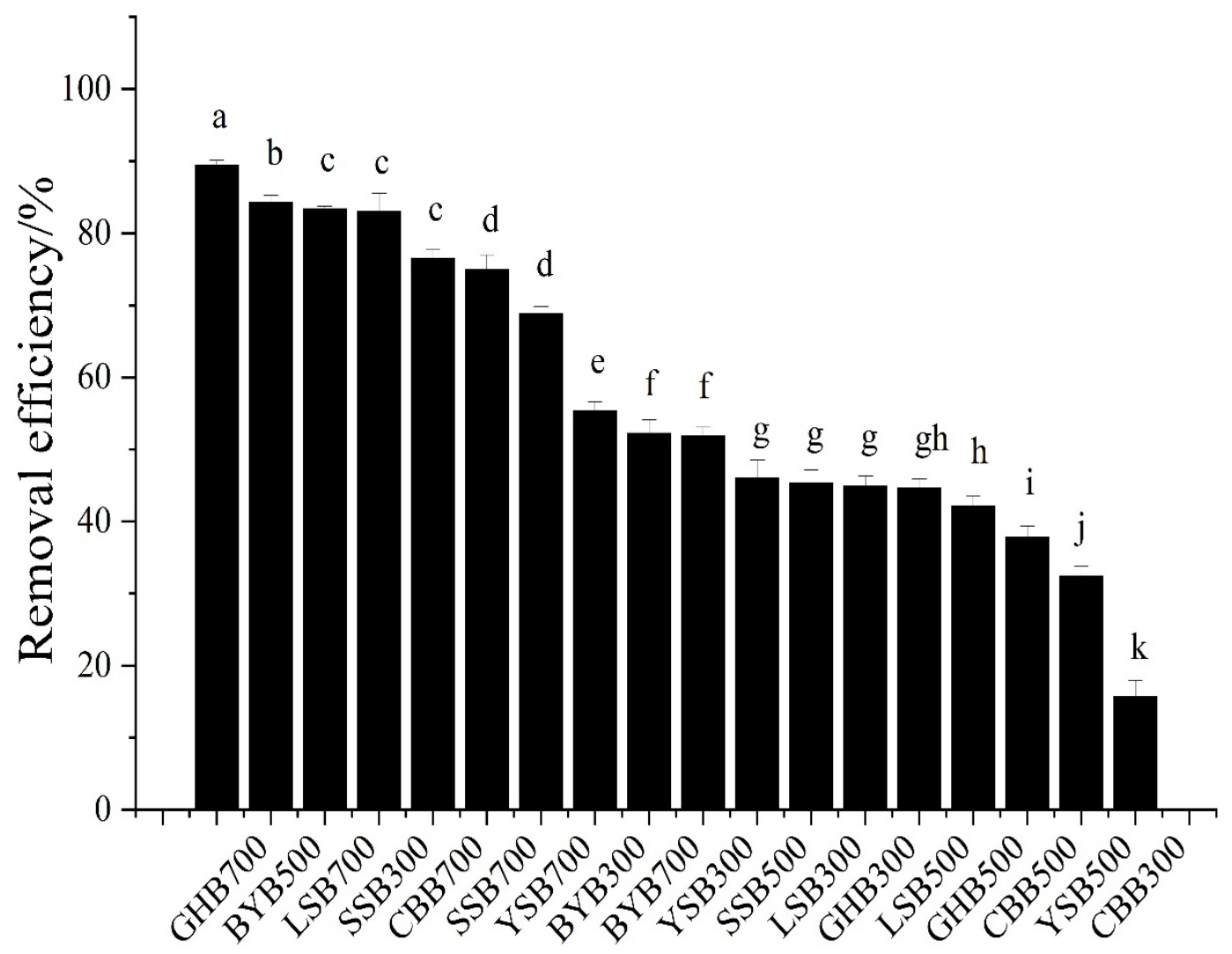

Figure 2. Comparison of different biochar removal efficiencies (initial $\mathrm{Cr}(\mathrm{VI})$ concentration: $50 \mathrm{mg} \cdot \mathrm{L}^{-1}$; dosage of biochar: $\left.1.2 \mathrm{~g} \cdot \mathrm{L}^{-1} ; \mathrm{pH}: 2\right)$, different letters show significant differences at $\alpha=0.05$. 


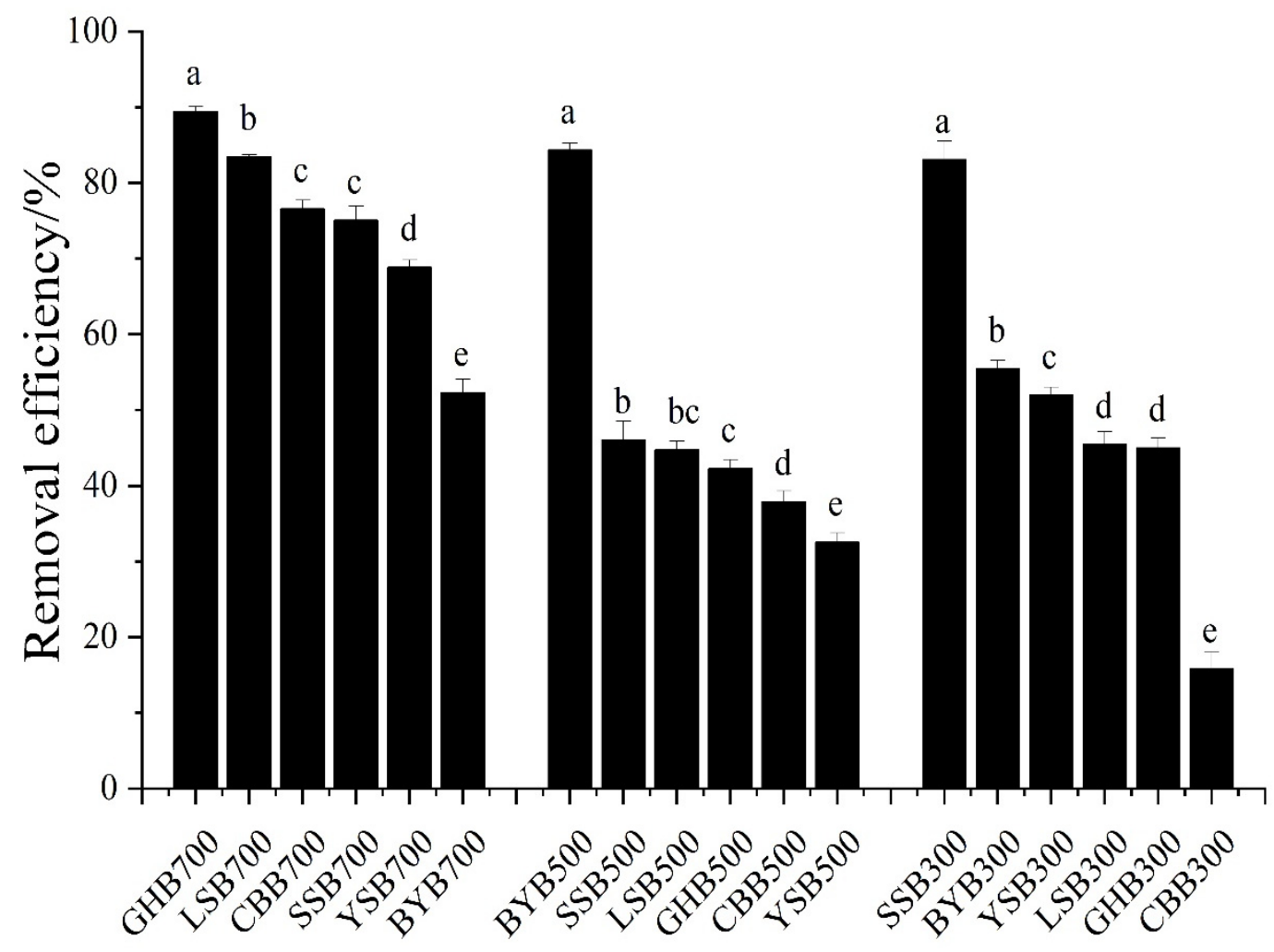

Figure 3. Comparison of biochar removal efficiencies under the same preparation conditions (initial Cr (VI) concentration: $50 \mathrm{mg} \cdot \mathrm{L}^{-1}$; dosage of biochar: $1.2 \mathrm{~g} \cdot \mathrm{L}^{-1} ; \mathrm{pH}$ : 2), different letters show significant differences at $\alpha=0.05$.

\subsection{Effect of Initial Concentration on Cr(VI) Removal}

As an important indicator of adsorption, the adsorption capacity of biochar was calculated by the Freundlich and Langmuir isotherm models [25]. The Langmuir isothermal model assumes that the surface of the adsorbent is consistent, the adsorption energy is the same everywhere, and the adsorption is on a monolayer. The adsorption capacity reaches the maximum provided the surface of adsorbent is saturated [25]. The Freundlich isotherm model assumes that the surface of the adsorbent is heterogeneous, and that the adsorption heat decreases exponentially with the increase of coverage. It can be applied to many cases of physical adsorption and chemical adsorption, and it can be well consistent with the experimental adsorption isotherm at the beginning and the middle bending part [13]. All the adsorption parameters are shown in Table 1 , and the isotherm model fitting results are shown in Figure 4 . The correlation coefficient $R^{2}$ calculated by Langmuir is greater than that calculated by Freundlich, which indicated that Langmuir can better explain the adsorption process of $\mathrm{Cr}(\mathrm{VI})$ on biochar prepared from different raw materials and temperatures. In general, the adsorption of $\mathrm{Cr}$ (VI) on biochar, in this study, belongs to chemical adsorption, which is a typical monolayer adsorption with uniform adsorption position. According to research reports, if the value of $1 / \mathrm{n}$ fitted by the Freundlich isotherm model is less than 1.0, the adsorption process is favorable; if the value of $1 / n$ is greater than 1.0 , the adsorption process is unfavorable $[26,27]$. The outcome showed that the adsorption process of $\mathrm{Cr}(\mathrm{VI})$ by biochar is a favorable adsorption process.

The maximum adsorption capacity of $\mathrm{Cr}$ (VI) on different biochar types can also be obtained by the Langmuir isotherm model (Table 1), the adsorption capacities from high to low were SSB300, BYB500, CBB700, GHB700, YSB700, LSB700, SSB700, BYB300, SSB500, YSB300, LSB300, GHB300, BYB700, LSB500, YSB500, CBB300, CBB500, GHB500 (51.39 $\mathrm{mg} \mathrm{g}^{-1}, 40.91 \mathrm{mg} \mathrm{g}^{-1}, 36.85 \mathrm{mg} \mathrm{g}^{-1}, 36.54 \mathrm{mg} \cdot \mathrm{g}^{-1}, 34.53 \mathrm{mg} \cdot \mathrm{g}^{-1}, 32.66 \mathrm{mg} \cdot \mathrm{g}^{-1}$, $26.34 \mathrm{mg} \cdot \mathrm{g}^{-1}, 25.96 \mathrm{mg} \cdot \mathrm{g}^{-1}, 20.04 \mathrm{mg} \cdot \mathrm{g}^{-1}, 16.18 \mathrm{mg} \mathrm{g}{ }^{-1}, 16.00 \mathrm{mg} \cdot \mathrm{g}^{-1}, 14.24 \mathrm{mg} \cdot \mathrm{g}^{-1}$, $\left.14.12 \mathrm{mg} \cdot \mathrm{g}^{-1}, 12.47 \mathrm{mg} \cdot \mathrm{g}^{-1}, 12.28 \mathrm{mg} \cdot \mathrm{g}^{-1}, 12.08 \mathrm{mg} \cdot \mathrm{g}^{-1}, 10.16 \mathrm{mg} \cdot \mathrm{g}^{-1}, 9.58 \mathrm{mg} \cdot \mathrm{g}^{-1}\right)$. 
It shows that the temperature of biochar had a great effect on the treatment of $\mathrm{Cr}$ (VI) pollution.

Table 1. Isotherm fitting results.

\begin{tabular}{|c|c|c|c|c|c|c|}
\hline \multirow{2}{*}{ Material } & \multicolumn{3}{|c|}{ Langmuir } & \multicolumn{3}{|c|}{ Freundlich } \\
\hline & k (L/mg) & $q_{m}\left(m g \cdot g^{-1}\right)$ & $\mathbf{R}^{2}$ & $\mathrm{~K}_{\mathrm{F}}\left(\mathrm{mg} \cdot \mathrm{g}^{-1}\right)$ & $1 / n$ & $\mathbf{R}^{2}$ \\
\hline SSB300 & 0.014 & 51.39 & 0.98 & 3.52 & 0.43 & 0.88 \\
\hline SSB500 & 0.065 & 20.04 & 0.95 & 5.56 & 0.22 & 0.68 \\
\hline SSB700 & 0.053 & 26.34 & 0.95 & 6.15 & 0.25 & 0.70 \\
\hline BYB300 & 0.012 & 25.96 & 0.94 & 1.85 & 0.42 & 0.88 \\
\hline BYB500 & 0.038 & 40.91 & 0.97 & 6.53 & 0.31 & 0.78 \\
\hline BYB700 & 0.038 & 14.12 & 0.91 & 2.71 & 0.28 & 0.91 \\
\hline YSB300 & 0.026 & 16.18 & 0.99 & 2.20 & 0.33 & 0.87 \\
\hline YSB500 & 0.033 & 12.28 & 0.96 & 2.04 & 0.30 & 0.90 \\
\hline YSB700 & 0.021 & 34.53 & 0.98 & 3.93 & 0.36 & 0.90 \\
\hline LSB300 & 0.023 & 16.00 & 0.97 & 2.04 & 0.34 & 0.89 \\
\hline LSB500 & 0.079 & 12.47 & 0.93 & 3.57 & 0.23 & 0.90 \\
\hline LSB700 & 0.042 & 32.66 & 0.92 & 6.40 & 0.28 & 0.70 \\
\hline GHB300 & 0.030 & 14.24 & 0.97 & 2.17 & 0.32 & 0.87 \\
\hline GHB500 & 0.118 & 9.58 & 0.92 & 3.49 & 0.19 & 0.90 \\
\hline GHB700 & 0.036 & 36.54 & 0.93 & 6.35 & 0.29 & 0.73 \\
\hline CBB300 & 0.011 & 12.08 & 0.94 & 0.81 & 0.43 & 0.92 \\
\hline CBB500 & 0.087 & 10.16 & 0.93 & 3.06 & 0.22 & 0.77 \\
\hline CBB700 & 0.036 & 36.85 & 0.97 & 6.35 & 0.30 & 0.78 \\
\hline
\end{tabular}

Note: $\mathrm{q}_{\mathrm{m}}$ : maximum adsorption capacity; $\mathrm{n}$ : Freundlich equilibrium parameter; $\mathrm{k}$ : Langmuir equilibrium parameter; $\mathrm{K}_{\mathrm{F}}$ : adsorption capacity; $\mathrm{R}^{2}$ : correlation coefficient.
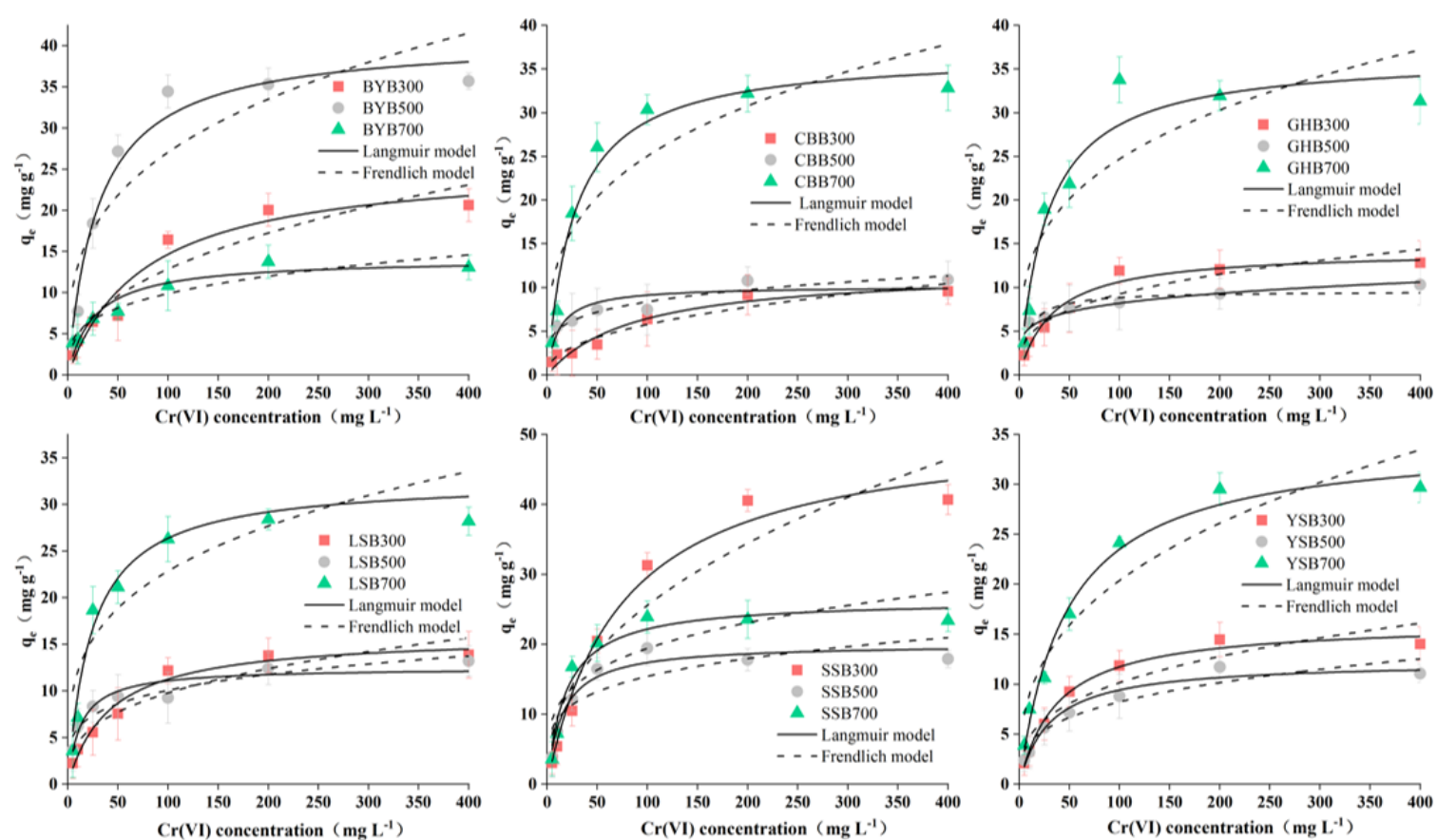

Figure 4. Isotherm fitting results of different biochar types ( $\mathrm{pH}: 2$; dosage of biochar: $1.2 \mathrm{~g} \cdot \mathrm{L}^{-1}$; reaction time: $1440 \mathrm{~min}$ ). 
The initial concentration had a great influence on the removal of $\mathrm{Cr}$ (VI) by biochar (Figure 5). When the initial Cr (VI) was 0-25 mg. $\mathrm{L}^{-1}$, SSB700, GHB700, LSB700, BYB500 and YSB700 can remove more than $90 \%$ or more $\mathrm{Cr}(\mathrm{VI})$. With the increase of the initial $\mathrm{Cr}$ (VI) concentration from $50 \mathrm{mg} \cdot \mathrm{L}^{-1}$ to $400 \mathrm{mg} \cdot \mathrm{L}^{-1}$, the removal efficiency of $\mathrm{Cr}$ (VI) decreased gradually, including $18.77 \%$ for SSB700, $16.73 \%$ for GHB700, $18.28 \%$ for BYB500, and $15.63 \%$ for YSB700. The removal efficiency of $\mathrm{Cr}(\mathrm{VI})$ decreased with the increase of initial concentration, probably due to the restricted number of active binding sites and newly formed thick layer on biochar [28]. When the $\mathrm{Cr}$ (VI) concentration was greater than $50 \mathrm{mg} \cdot \mathrm{L}^{-1}$, the adsorption site on the surface of biochar was saturated and could not be further adsorbed to remove $\mathrm{Cr}(\mathrm{VI})$, leading to a decrease in the amount of $\mathrm{Cr}(\mathrm{VI})$ diffusion to the surface of biochar in the solution [29]. In addition, the increase in $\mathrm{Cr}$ (VI) concentration led to the formation of a new thick layer on the surface of biochar, which further depleted the capacity of biochar and impeded the binding of $\mathrm{Cr}$ (VI) to biochar. However, the adsorption capacity $\left(\mathrm{q}_{\mathrm{e}}\right)$ of biochar on $\mathrm{Cr}(\mathrm{VI})$ increased with the increase of initial $\mathrm{Cr}(\mathrm{VI})$ concentration (Figure 4). This was due to the increased driving force supplied by the increase of $\mathrm{Cr}(\mathrm{VI})$ concentration [23]. When the $\mathrm{Cr}(\mathrm{VI})$ concentration increased from 5 to $100 \mathrm{mg} \cdot \mathrm{L}^{-1}$, biochar on the adsorption of $\mathrm{Cr}(\mathrm{VI})$ had increased dramatically, after that, when the $\mathrm{Cr}(\mathrm{VI})$ concentration increased from 100 to $400 \mathrm{mg} \cdot \mathrm{L}^{-1}$, within the scope of the biochar adsorption quantity growth slowed, probably because the number of active sites available on biochar was limited, thus, it could not meet the increased number of $\mathrm{Cr}(\mathrm{VI})$ ions.
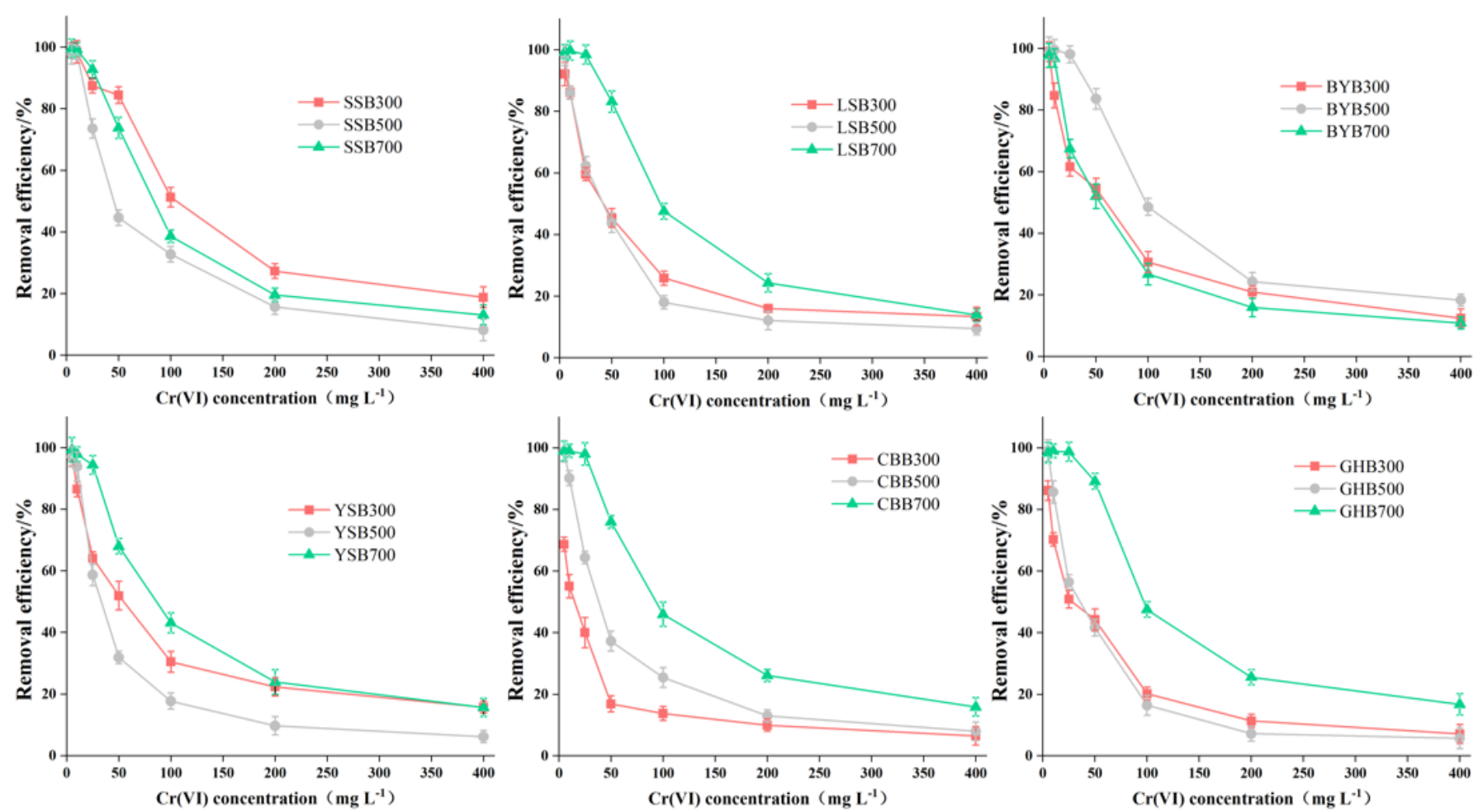

Figure 5. Relationship between initial concentration and $\mathrm{Cr}(\mathrm{VI})$ removal efficiency ( $\mathrm{pH}$ : 2; dosage of biochar: $1.2 \mathrm{~g} \cdot \mathrm{L}^{-1}$; reaction time: $1440 \mathrm{~min})$.

\subsection{Removal Kinetics}

The pseudo first-order and pseudo second-order kinetic models were similar in that they all consider the difference between the equilibrium adsorption capacity and the adsorption capacity at time $t\left(\mathrm{q}_{\mathrm{e}}-\mathrm{q}_{\mathrm{t}}\right)$ as the driving force for the adsorption reaction [30,31]. However, the difference was that in the pseudo first-order kinetics, the adsorption efficiency was proportional to the first power of the driving force and the adsorption was controlled 
by the diffusion step. If the experimental data have a good goodness of fit for the pseudo first-order kinetics, it indicates that the adsorption reaction is mainly attributed to the physical adsorption process [8]. The pseudo secondary dynamics model assumes that the adsorption capacity is proportional to the surface of the adsorbent that has not taken the active site of the square of the number of values. If the experimental data can be better fitted with the pseudo second-order model, it shows that the reaction is controlled by a chemical adsorption process and the process involves the adsorbent material between the solute and electronic sharing or transfer [32,33]. Adsorption kinetics data were fitted by the following two models: pseudo first-order and pseudo second-order kinetics models. The fitted kinetic parameters are shown in Table 2 and the corresponding curves are shown in Figure 6. The high correlation coefficient $\mathrm{R}^{2}$ indicates that the pseudo second-order model is superior to the pseudo first-order model. Therefore, the most likely mechanism for the removal of $\mathrm{Cr}(\mathrm{VI})$ is chemisorption $[17,27]$.

Table 2. Kinetic fitting results.

\begin{tabular}{|c|c|c|c|c|c|c|}
\hline \multirow{2}{*}{ Material } & \multicolumn{3}{|c|}{ Pseudo-First Order Model } & \multicolumn{3}{|c|}{ Pseudo-Second Order Model } \\
\hline & $k_{1}\left(\min ^{-1}\right)$ & $\mathrm{q}_{\mathrm{e}}\left(\mathrm{mg} \cdot \mathrm{g}^{-1}\right)$ & $\mathbf{R}^{2}$ & $\underset{\left(\mathrm{g} \cdot \mathrm{mg}^{-1} \cdot \mathrm{min}^{-1}\right)}{\stackrel{\mathrm{k}_{2}}{ }}$ & $\mathrm{q}_{\mathrm{e}}$ & $\mathbf{R}^{2}$ \\
\hline SSB300 & 0.007 & 19.38 & 0.89 & 0.043 & 21.96 & 0.93 \\
\hline SSB500 & 0.011 & 14.96 & 0.95 & 0.0008 & 16.59 & 0.98 \\
\hline SSB700 & 0.091 & 18.41 & 0.82 & 0.0060 & 19.66 & 0.93 \\
\hline BYB300 & 0.020 & 6.44 & 0.83 & 0.029 & 6.94 & 0.94 \\
\hline BYB500 & 0.076 & 24.52 & 0.88 & 0.111 & 25.96 & 0.98 \\
\hline BYB700 & 0.021 & 6.91 & 0.85 & 0.030 & 7.46 & 0.94 \\
\hline YSB300 & 0.040 & 7.87 & 0.83 & 0.057 & 8.44 & 0.94 \\
\hline YSB500 & 0.044 & 6.37 & 0.87 & 0.059 & 6.87 & 0.96 \\
\hline YSB700 & 0.019 & 15.13 & 0.90 & 0.027 & 16.36 & 0.97 \\
\hline LSB300 & 0.036 & 6.90 & 0.93 & 0.050 & 7.43 & 0.98 \\
\hline LSB500 & 0.040 & 8.53 & 0.87 & 0.058 & 9.13 & 0.97 \\
\hline LSB700 & 0.027 & 18.66 & 0.92 & 0.037 & 20.13 & 0.98 \\
\hline GHB300 & 0.051 & 6.61 & 0.91 & 0.067 & 7.11 & 0.95 \\
\hline GHB500 & 0.039 & 7.72 & 0.93 & 0.053 & 8.31 & 0.97 \\
\hline GHB700 & 0.027 & 18.20 & 0.90 & 0.038 & 19.65 & 0.95 \\
\hline CBB300 & 0.047 & 6.41 & 0.87 & 0.062 & 6.92 & 0.95 \\
\hline CBB500 & 0.046 & 6.41 & 0.87 & 0.062 & 6.90 & 0.94 \\
\hline CBB700 & 0.020 & 22.22 & 0.87 & 0.027 & 24.21 & 0.95 \\
\hline
\end{tabular}

Note: qe: adsorption capacity at equilibrium; K1, K2: constants; $\mathrm{R}^{2}$ : correlation coefficient.

The change of $\mathrm{Cr}(\mathrm{VI})$ concentration in the solution within a certain period of time is shown in Figure 6. For the same initial Cr (VI) concentration, rapid adsorption occurs from the beginning of the reaction to $360 \mathrm{~min}$. Then, there is a relative equilibrium state lasting until $1440 \mathrm{~min}$. Originally, the rapid adsorption may be due to the maximum number of adsorption sites, which were gradually occupied by $\mathrm{Cr}(\mathrm{VI})$, leading to the gradual slow adsorption efficiency [16,17]. 

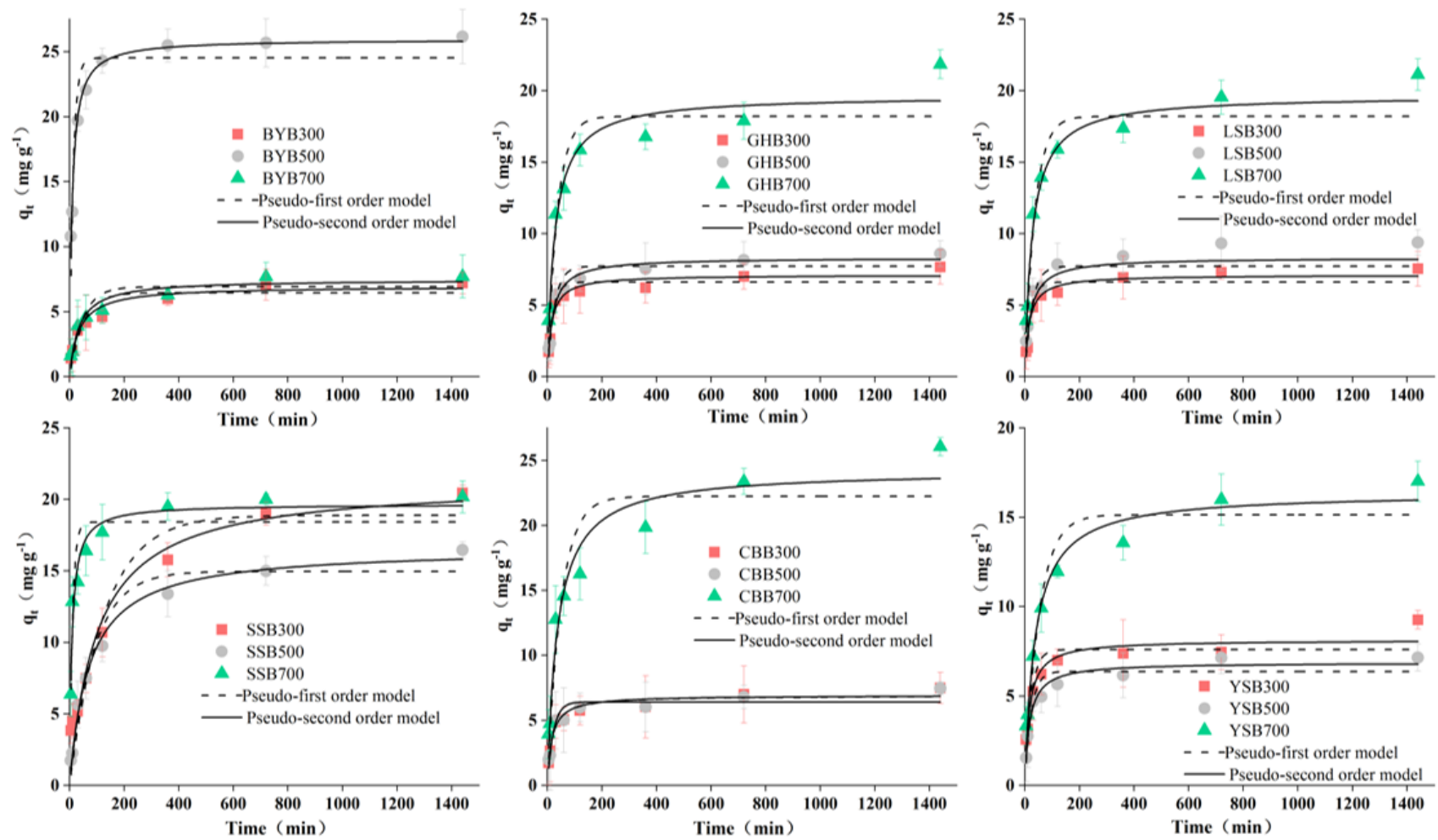

Figure 6. Kinetics fitting results of different biochar types (pH: 2.0; dosage of biochar: $1.2 \mathrm{~g} \cdot \mathrm{L}^{-1}$; $\mathrm{Cr}$ (VI) concentration: $\left.50 \mathrm{mg} \cdot \mathrm{L}^{-1}\right)$.

\section{Conclusions}

The results showed that the biochar prepared from different garden wastes can effectively remove $\mathrm{Cr}(\mathrm{VI})$ under acidic conditions. The $\mathrm{Cr}(\mathrm{VI})$ removal process in aqueous waste was highly dependent on $\mathrm{pH}$, and the highest removal efficiency was observed at $\mathrm{pH}$ 2.0. The pseudo-second-order kinetic model was the optimum model for $\mathrm{Cr}$ (VI) removal, the reaction belongs to the chemical adsorption, $\mathrm{Cr}$ was not uniformly distributed on biochar. The Langmuir isotherm model was the best model for $\mathrm{Cr}(\mathrm{VI})$ removal. It showed that using biochar to remove $\mathrm{Cr}$ (VI) followed electrostatic attraction, $\mathrm{Cr}$ (VI) to $\mathrm{Cr}$ (III) and the rule of the complexation. The garden waste biochar used in this study exhibited a comparable or relatively slower removal rate of $\mathrm{Cr}(\mathrm{VI})$ compared to commercial activated carbon; however, the effective $\mathrm{Cr}(\mathrm{VI})$ removal and relatively lower cost of biochar make it a sustainable remedial medium for large-scale applications. In general, SSB300, BYB500, GHB700, LSB700, YSB700, CBB700 were promising adsorbents for the treatment of Cr (VI) pollution in acidic wastewater.

Author Contributions: Conceptualization, J.-H.C. and J.-J.Y.; Data curation, Q.-C.Z. and C.-C.W.; Formal analysis, C.-C.W.; Funding acquisition, C.-L.Z.; Investigation, Q.-C.Z.; Software, Q.-C.Z.; Supervision, J.-H.C.; Writing-original draft, Q.-C.Z.; Revision, C.-L.Z. All authors have read and agreed to the published version of the manuscript.

Funding: This work was supported by the National key R\&D plan (Research on the construction technology of new soil into nature and the topography of the coal mining slash in the national key research and development plan) (grant number: 2017YFC0504404]), Key R\&D plan of Ningxia Hui Autonomous Region (Study on the technology of Terrain Reconstruction and soil reconstruction of open-pit coal mining footprint in Helan Mountain reserve) (grant number: 2018BFG02002), Special Cultivation Project for Reform and Development of Beijing Academy of Science and Technology (Research on key technologies of energy-saving and high-efficiency thermal cracking of garden waste and development of experimental equipment) (grant number: 2021G-0002). 
Institutional Review Board Statement: Not applicable.

Informed Consent Statement: Not applicable.

Data Availability Statement: The data presented in this study are available on request from the corresponding author.

Conflicts of Interest: The authors declare no conflict of interest.

\section{References}

1. Abdel-Fattah, T.M.; Mahmoud, M.E.; Ahmed, S.B.; Huff, M.D.; Lee, J.W.; Kumar, S. Biochar from woody biomass for removing metal contaminants and carbon sequestration. J. Ind. Eng. Chem. 2015, 22, 103-109. [CrossRef]

2. Ahmad, M.; Rajapaksha, A.U.; Lim, J.E.; Zhang, M.; Bolan, N.; Mohan, D.; Vithanage, M.; Lee, S.S.; Ok, Y.S. Biochar as a sorbent for contaminant management in soil and water: A review. Chemosphere 2014, 99, 19-33. [CrossRef] [PubMed]

3. Ahmadi, M.; Kouhgardi, E.; Ramavandi, B. Physico-chemical study of dew melon peel biochar for chromium attenuation from simulated and actual wastewaters. Korean J. Chem. Eng. 2016, 33, 2589-2601. [CrossRef]

4. Al-Ghouti, M.A.; Da'ana, D.A. Guidelines for the use and interpretation of adsorption isotherm models: A review. J. Hazard. Mater. 2020, 393, 122383. [CrossRef] [PubMed]

5. Aram, F.; García, E.H.; Solgi, E.; Mansournia, S. Urban green space cooling effect in cities. Heliyon 2019, 5, 1339. [CrossRef] [PubMed]

6. Bureau, B.G.A.G. Suggestions on Speeding up the Scientific Disposal and Utilization of Landscape Waste. 2019. Available online: http:/ /yllhj.beijing.gov.cn/zwgk/fgwj/qtwj/201911/t20191130_766793.shtml (accessed on 3 July 2018).

7. Chen, M.; Nong, S.; Zhao, Y.; Riaz, M.S.; Xiao, Y.; Molokeev, M.S.; Huang, F. Renewable P-type zeolite for superior absorption of heavy metals: Isotherms, kinetics, and mechanism. Sci. Total. Environ. 2020, 726, 138535. [CrossRef]

8. Chen, X.; Dai, Y.; Fan, J.; Xu, X.; Cao, X. Application of iron-biochar composite in topsoil for simultaneous remediation of chromium-contaminated soil and groundwater: Immobilization mechanism and long-term stability. J. Hazard. Mater. 2020, 405, 124226. [CrossRef]

9. Choudhary, B.; Paul, D. Isotherms, kinetics and thermodynamics of hexavalent chromium removal using biochar. J. Environ. Chem. Eng. 2018, 6, 2335-2343. [CrossRef]

10. Chowdhury, S.; Mishra, R.; Saha, P.; Kushwaha, P. Adsorption thermodynamics, kinetics and isosteric heat of adsorption of malachite green onto chemically modified rice husk. Desalination 2010, 265, 159-168. [CrossRef]

11. Dong, X.; Ma, L.Q.; Gress, J.; Harris, W.; Li, Y. Enhanced Cr(VI) reduction and As(III) oxidation in ice phase: Important role of dissolved organic matter from biochar. J. Hazard. Mater. 2014, 267C, 62-70. [CrossRef]

12. Dong, X.; Ma, L.Q.; Li, Y. Characteristics and mechanisms of hexavalent chromium removal by biochar from sugar beet tailing. $J$. Hazard. Mater. 2011, 190, 909-915. [CrossRef]

13. Guo, X.; Ji, Q.; Rizwan, M.; Li, H.; Li, D.; Chen, G. Effects of biochar and foliar application of selenium on the uptake and subcellular distribution of chromium in Ipomoea aquatica in chromium-polluted soils. Ecotoxicol. Environ. Saf. 2020, 206, 111184. [CrossRef]

14. Kera, N.H.; Bhaumik, M.; Pillay, K.; Ray, S.S.; Maity, A. Selective removal of toxic Cr(VI) from aqueous solution by adsorption combined with reduction at a magnetic nanocomposite surface. J. Colloid Interface Sci. 2017, 503, 214-228. [CrossRef]

15. Houben, D.; Evrard, L.; Sonnet, P. Beneficial effects of biochar application to contaminated soils on the bioavailability of $\mathrm{Cd}$, $\mathrm{Pb}$ and $\mathrm{Zn}$ and the biomass production of rapeseed (Brassica napus L.). Biomass Bioenergy 2013, 57, 196-204. [CrossRef]

16. Huang, X.; Liu, Y.; Liu, S.; Tan, X.; Ding, Y.; Zeng, G.; Zhou, Y.; Zhang, M.; Wang, S.; Zheng, B. Effective removal of Cr(VI) using $\beta$-cyclodextrin-chitosan modified biochars with adsorption/reduction bifuctional roles. Rsc Adv. 2015, 6, 94-104. [CrossRef]

17. Rafique, M.I.; Usman, A.R.; Ahmad, M.; Al-Wabel, M.I. Immobilization and mitigation of chromium toxicity in aqueous solutions and tannery waste-contaminated soil using biochar and polymer-modified biochar. Chemosphere 2021, 266, 129198. [CrossRef] [PubMed]

18. Liu, L.; Liu, G.; Zhou, J.; Jin, R. Interaction between hexavalent chromium and biologically formed iron mineral-biochar composites: Kinetics, products and mechanisms. J. Hazard. Mater. 2021, 405, 124246. [CrossRef]

19. Liu, N.; Zhang, Y.; Xu, C.; Liu, P.; Lv, J.; Liu, Y.; Wang, Q. Removal mechanisms of aqueous Cr(VI) using apple wood biochar: A spectroscopic study. J. Hazard. Mater. 2020, 384, 121371. [CrossRef] [PubMed]

20. Mohan, D.; Rajput, S.; Singh, V.K.; Steele, P.H.; Pittman, C.U. Modeling and evaluation of chromium remediation from water using low cost bio-char, a green adsorbent. J. Hazard. Mater. 2011, 188, 319-333. [CrossRef]

21. Nastran, M.; Kobal, M.; Eler, K. Urban heat islands in relation to green land use in European cities. Urban For. Urban Green. 2018, 37, 33-41. [CrossRef]

22. Yaashikaa, P.R.; Kumar, P.S.; Varjani, S.; Saravanan, A. A critical review on the biochar production techniques, characterization, stability and applications for circular bioeconomy. Biotechnol. Rep. 2020, 28, e00570. [CrossRef]

23. Pang, Y.; Zeng, G.; Tang, L.; Zhang, Y.; Liu, Y.; Lei, X.; Li, Z.; Zhang, J.; Liu, Z.; Xiong, Y. Preparation and application of stability enhanced magnetic nanoparticles for rapid removal of $\mathrm{Cr}(\mathrm{VI})$. Chem. Eng. J. 2011, 175, 222-227. [CrossRef] 
24. Qu, J.; Wang, Y.; Tian, X.; Jiang, Z.; Deng, F.; Tao, Y.; Jiang, Q.; Wang, L.; Zhang, Y. KOH-activated porous biochar with high specific surface area for adsorptive removal of chromium (VI) and naphthalene from water: Affecting factors, mechanisms and reusability exploration. J. Hazard. Mater. 2021, 401, 123292. [CrossRef]

25. Radi, S.; Abiad, C.E.; Moura, N.M.M.; Faustino, M.A.F.; Neves, M.G.P.M.S. New hybrid adsorbent based on porphyrin functionalized silica for heavy metals removal: Synthesis, characterization, isotherms, kinetics and thermodynamics studies. J. Hazard. Mater. 2019, 370, 80-90. [CrossRef] [PubMed]

26. Rajapaksha, A.U.; Alam, M.S.; Chen, N.; Alessi, D.S.; Igalavithana, A.D.; Tsang, D.C.W.; Ok, Y.S. Removal of hexavalent chromium in aqueous solutions using biochar: Chemical and spectroscopic investigations. Sci. Total. Environ. 2018, 625, 1567-1573. [CrossRef] [PubMed]

27. Tan, X.; Liu, Y.; Zeng, G.; Wang, X.; Hu, X.; Gu, Y.; Yang, Z. Application of biochar for the removal of pollutants from aqueous solutions. Chemosphere 2015, 125, 70-85. [CrossRef] [PubMed]

28. Wang, J.; Guo, X. Adsorption kinetic models: Physical meanings, applications, and solving methods. J. Hazard. Mater. 2020, 390, 122156. [CrossRef]

29. Wang, X.S.; Chen, L.F.; Li, F.Y.; Chen, K.L.; Wan, W.Y.; Tang, Y.J. Removal of Cr (VI) with wheat-residue derived black carbon: Reaction mechanism and adsorption performance. J. Hazard. Mater. 2010, 175, 816-822. [CrossRef]

30. Xiao, W.; Ye, X.; Zhu, Z.; Zhang, Q.; Zhao, S.; Chen, D.; Gao, N.; Hu, J. Combined effects of rice straw-derived biochar and water management on transformation of chromium and its uptake by rice in contaminated soils. Ecotoxicol. Environ. Saf. 2021, 208, 111506. [CrossRef]

31. Yang, X.; Wan, Y.; Zheng, Y.; He, F.; Yu, Z.; Huang, J.; Wang, H.; Ok, Y.S.; Jiang, Y.; Gao, B. Surface functional groups of carbon-based adsorbents and their roles in the removal of heavy metals from aqueous solutions: A critical review. Chem. Eng. J. 2019, 366, 608-621. [CrossRef]

32. Zhang, J.; Chen, S.; Zhang, H.; Wang, X. Removal behaviors and mechanisms of hexavalent chromium from aqueous solution by cephalosporin residue and derived chars. Bioresour. Technol. 2017, 238, 484-491. [CrossRef] [PubMed]

33. Zhang, Q.; Wang, C. Natural and Human Factors Affect the Distribution of Soil Heavy Metal Pollution: A Review. Water Air Soil Pollut. 2020, 231, 350. [CrossRef] 